\title{
UNUSUAL CASE OF RETROPANCREATIC MASS INVOLVING PORTAL VEIN
}

\author{
Rajesh Poudel ${ }^{1}$, Subodh K Adhikari ${ }^{2}$, Surendra Basnet ${ }^{3}$, Arjun Acharya ${ }^{4}$, Sarad Pokhrel ${ }^{5}$
}

\begin{abstract}
Retroperitoneal Tumors are relatively rare and usually present in locally advanced stage. They present special therapeutic challenges because of their location and frequent intimate association with major vessels in retroperitoneum. Herein, we present a case report of a patient with retropancreatic mass along with features of portal hypertension in CT scan. Intraoperatively tumor was adhered to portal vein, resection and anastomosis of Portal Vein with excision of tumor was done. Leiomysarcoma was diagnosed after histopathology and immunohistochemistry report.
\end{abstract}

KEYWORDS: Leiomyosarcoma, portal vein, retroperitoneal tumors, sarcoma

1. Lecturer, Department of Surgery, Universal College of Medical Sciences \& Teaching hospital, Bhairahawa, Nepal

2. Professor, Surgical Gastroenterology unit, Department of Surgery, National Academy of Medical Sciences, Bir Hospital, Kathmandu, Nepal

3. Consultant Surgeon, Department of Surgery, NAMS, Bir Hospital.

4. Consultant Surgeon, Western Regional Hospital, Pokhara, Nepal

5. M.Ch. Resident, Surgical Gastroenterololgy, National Academy of Medical Sciences, Kathmandu, Nepal

\author{
For Correspondence \\ Dr. Rajesh Poudel \\ Lecturer, Department of Surgery, \\ Universal College of Medical Sciences \& Teaching Hospital, \\ Bhairahawa, Nepal \\ E-mail: rajeshpoudel@yahoo.com
}




\section{INTRODUCTION}

Sarcomas are malignant tumors arising from mesenchymal cell lines. Leiomyosarcoma is an aggressive soft tissue sarcoma derived from smooth muscle cells typically of uterine gastrointestinal or soft tissue origin. Leiomyosarcoma consists of $5 \%$ to $10 \%$ of all soft tissue sarcoma. ${ }^{1} 10 \%$ to $20 \%$ of soft tissue sarcomas occur in the retroperitoneum. ${ }^{2-6}$ In a population-based series reported in the Surveillance, Epidemiology, and End Results (SEER) database, the average annual incidence of retroperitoneal sarcomas was approximately 2.7 cases per million population. ${ }^{7}$ Because of their location and frequent intimate association with several structures in the retroperitoneum involving major vessels, they posses special therapeutic challenge.

\section{CASE REPORT}

30 Years old male admitted in our department with complain of pain in epigastric region for 1 month and a palpable lump in abdomen for 2 weeks. On examination there was a palpable abdominal mass of about $6 \times 5 \mathrm{~cm}$ in epigastric region, which was non-tender smooth surfaced and was not moving with respiration. USG Abdomen and Pelvis revealedlarge solid mass at pancreatic head region measuring $8.0 \times 5.0 \mathrm{~cm}$ in size. CT scan of Abdomen revealed well defined heterogeneously enhancing soft tissue density mass lesion measuring 9.4 X 6.8 $\mathrm{X} 6.6 \mathrm{~cm}$ in sub hepatic region mainly in the midline with slight predominance to right. Lesion was abutting main portal vein with effacement of the lumen with multiple torturous collaterals in the porta hepatis. There were dilated and torturous submucosal vein in the whole of the stomach. Spleen was enlarged. Inferiorly the lesion was abutting the pancreas with its inferior displacement. Posteriorly the lesion was abutting and effacing IVC (Fig. 1). UGI endoscopy reveals External compression of Duodenal bulb otherwise normal. CA $19-9$ was $23.98 \mathrm{U} / \mathrm{mL}$. Exploratory Laparotomy was done. Operative findings were $10 \times 10 \mathrm{~cm}$ firm mass with areas of necrosis in retroperitoneum densely adhered to Portal vein and CBD which were pushed anteriorly (Fig 2). Multiple collaterals veins and splenomegaly were present suggestive of portal hypertension. Tumor was excised in toto with segmental resection and anastomosis of portal vein. Cut section of tumor shows whitish tan solid and trabeculated surface (fig 3)Histopathology reports revealed Malignant Soft tissue Sarcoma, French Federation of Cancer Centers Sarcoma Group grading system(FNCLCC) grade2. Immuno histo chemistry was positive for smooth muscle actin (SMA). So final diagnosis of Leiomyosarcoma was made. Post operative period was uneventful and patient was discharged on $15^{\text {th }}$ day of surgery.

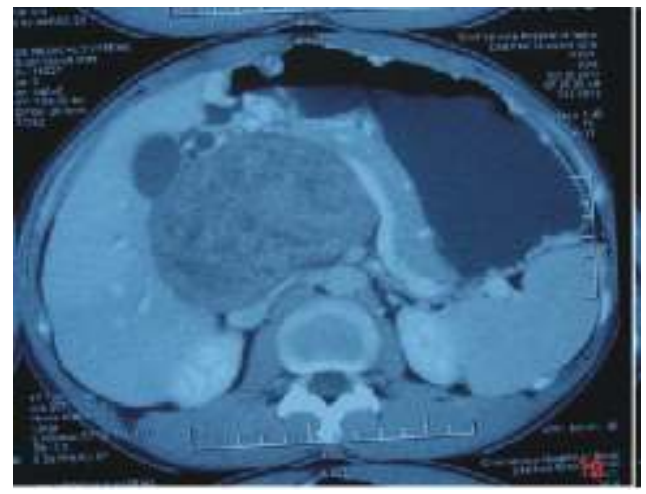

Figure 1. Retroperitoneal mass pushing the pancreas anteriorly and multiple collaterals around porta hepatis

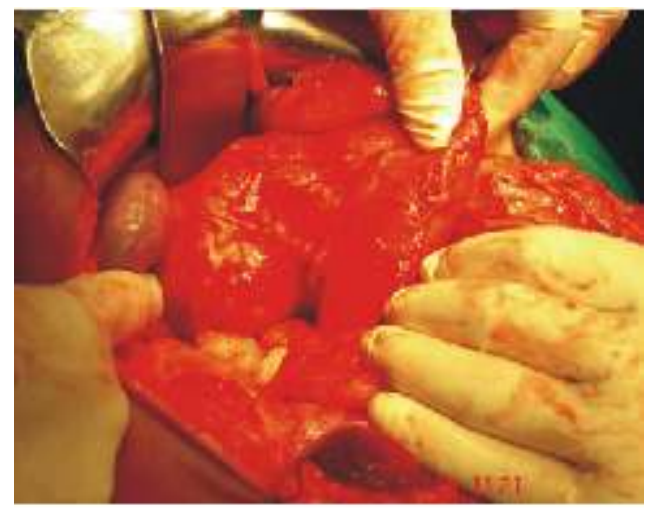

Figure 2. Mass densely adhered to duodenum

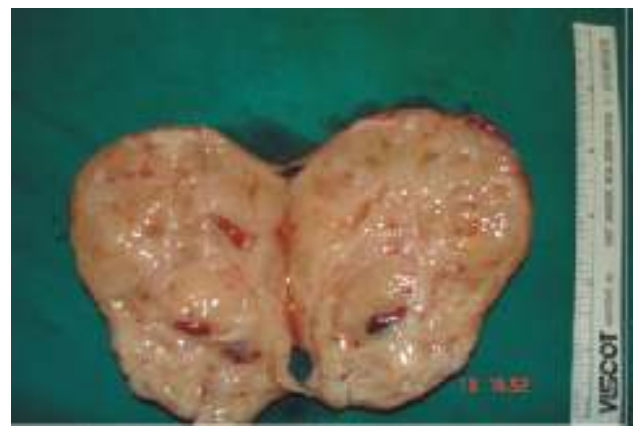

Figure 3. Cut Section of the mass

\section{DISCUSSION}

Retroperitoneal sarcomas are uncommon neoplasms and account for $10-15 \%$ of all sarcomas. Leiomyosarcoma is second most common (12-39\%) Retroperitoneal Sarcoma after Liposarcoma (25-60\%). ${ }^{8}$ The number of patients with retroperitoneal soft tissue sarcomas requiring major vascular resections is unknown. In a study done by Schwarzbach MH et al the frequency of retroperitoneal vascular involvement was $17.7 \%{ }^{9}$ 
Retroperitoneal leiomyosarcoma occurs most commonly in the fifth to seventh decade. ${ }^{2-5}$ Retroperitoneal tumors typically have vague presenting symptoms. These tumors are provided with a well-concealed, widely expansible area, leading to the development of large masses with local and distant metastases before the patient becomes symptomatic. The studies of Cody et al and Braasch et al both reported abdominal pain and weight loss were the most common symptoms. ${ }^{3,10}$

Computed tomography (CT-scan) or magnetic resonance image (MRI) are the most useful tools for investigation and evaluation of retroperitoneal mass. These explorations demonstrated the retroperitoneal origin of the tumor and also could assess the relationships with other organs (kidney, suprarenal glands, liver, and vessels), but could even discover possible intra-abdominal metastasis or bone invasion. MRI offer a better evaluation of the retroperitoneum, few studies emphasized the importance of axial images in addition to sagittal and coronal views. ${ }^{11} \mathrm{~A}$ leiomyosarcoma on CT and magnetic resonance imaging is typically a nonfatty, irregularly marginated, heterogeneous mass without calcification. Ultrasound and angiography may be useful in delineating tumor vessels or vascular infiltration if these are suspected from other studies. ${ }^{10,12}$

$77 \%$ of retroperitoneal sarcoma-related deaths were shown to be caused by local recurrence without concomitant metastasis. ${ }^{13}$ Local control is therefore important in the treatment of adult patients with retroperitoneal soft tissue sarcoma.

Surgery is the main treatment factor in the outcome of retroperitoneal leiomyosarcoma. ${ }^{14}$ Complete surgical resection with at least $3 \mathrm{~cm}$ margins is the treatment of choice but is rarely feasible due to invasion of adjacent structures by the tumor. ${ }^{6}$ The use of vascular resection is the treatment of choice in sarcomas that involve major blood vessels in the retroperitoneum. With this technique, most patients with vascular involvement can be treated by complete resection with tumor-free resection margins.

There are few studies offering evidence of effective radiotherapy for retroperitoneal leiomyosarcoma. Svarvar et al reviewed 225 patients with nonvisceral soft tissue leiomyosarcomas, and there was no significant difference between complete surgical resection with or without adjuvant radiotherapy in the long-term prognosis. Multivariate analysis of the cases showed that a higher grade malignancy, large tumors, and deep tumors were correlated significantly with decreased metastasis-free survival. Inadequate local treatment was correlated with local recurrence, and a high grade of malignancy was correlated with decreased overall survival. ${ }^{15}$

\section{CONCLUSION}

Retroperitoneal Leiomyosarcomas are rare entities. Because of their location, they frequently involve major vessels, which possess special therapeutic challenge.Despite the advancement in radiation therapy and medical treatment for sarcomas, complete surgical removal with the negative margins remains the mainstay of the treatment. Tumor involving major vessel may be resected and reconstructed when required. 


\section{REFERENCES}

1. Gustafson P, Willen H, Baldetorp B, Fernö M, Akerman M, Rydholm A. Soft tissue leiomyosarcoma. Cancer. 1992;70:114-9.

2. Adam Y, Osland J, Harvey A, Reif R. Primary retroperitoneal soft-tissue sarcomas. J Surg Oncol 1984;25:8-11.?

3. Cody H3, Turnbull AD, Fortner JG, Hajdu SI. The continuing challenge of retroperitoneal sarcomas. Cancer. 1981 May 1;47(9):2147-52.

4. McGrath PC, Neifeld JP, Lawrence Jr WA, DeMay RM, Kay SA, Horsley 3rd JS, Parker GA. Improved survival following complete excision of retroperitoneal sarcomas. Annals of surgery. 1984 Aug;200(2):200.

5. Catton CN, O'Sullivan B, Kotwall C, Cummings B, Hao Y, Fornasier V. Outcome and prognosis in retroperitoneal soft tissue sarcoma. International Journal of Radiation Oncology* Biology* Physics. 1994 Jul 30;29(5):1005-10.

6. Todd CS, Michael H, Sutton G. Retroperitoneal leiomyosarcoma: eight cases and a literature review. Gynecologic oncology. 1995 Dec 31;59(3):333-7.

7. Dalal KM, Kattan MW, Antonescu CR, Brennan MF, Singer S. Subtype specific prognostic nomogram for patients with primary liposarcoma of the retroperitoneum, extremity, or trunk. Annals of surgery. 2006 Sep 1;244(3):381-91.

8. Misra S, Chaturvedi A. Management of retroperitoneal sarcoma. In: Taylor I, Johnson CD, editors. Recent advances in surgery. New Delhi: Jaypees; 2011. pp. 205-220.
9. Schwarzbach MH, Hormann Y, Hinz U, Leowardi C, Böckler D, Mechtersheimer $G$, Friess $H$, Büchler MW, Allenberg JR. Clinical results of surgery for retroperitoneal sarcoma with major blood vessel involvement. Journal of vascular surgery. 2006 Jul 31;44(1):46-55.

10. Braasch JW, Mon AB. Primary retroperitoneal tumors. The Surgical clinics of North America. 1967 Jun;47(3):663-78.

11. Windham TC, Pisters PW. Retroperitoneal sarcomas. Cancer control. 2005; 12(1):36-43.

12. Hartman DS, Hayes WS, Choyke PL, Tibbetts GP. From the archives of the AFIP. Leiomyosarcoma of the retroperitoneum and inferior vena cava: radiologic-pathologic correlation. Radiographics. 1992 Nov;12(6):1203-20.

13. Stojadinovic A, Yeh A, Brennan MF. Completely resected recurrent soft tissue sarcoma: primary anatomic site governs outcomes. Journal of the American College of Surgeons. 2002 Apr 30;194(4):436-47.

14. Stoeckle E, Coindre JM, Bonvalot S, Kantor G, Terrier P, Bonichon F, Nguyen Bui B. Prognostic factors in retroperitoneal sarcoma. Cancer. 2001 Jul 15;92(2):359-68.

15. Svarvar C, Böhling T, Berlin Ö, Gustafson P, Follerås G, Bjerkehagen B, Domanski HA, Sundby Hall K, Tukiainen E, Blomqvist C. Clinical course of nonvisceral soft tissue leiomyosarcoma in 225 patients from the Scandinavian Sarcoma Group. Cancer. 2007 Jan 15;109(2):282-91. 